\title{
Advances in extreme value analysis and application to natural hazards
}

\author{
Ivan D. Haigh ${ }^{1} \cdot$ Thomas Wahl $^{2}$
}

Published online: 22 August 2019

(c) Springer Nature B.V. 2019

The last decade has seen a dramatic increase in damages associated with natural hazards, with the two costliest years ever, 2011 and 2017, resulting in US\$330 bn and US\$360 bn overall losses (Löw 2018). Despite recent improvements in protection measures (e.g. flood defences, earthquake-resistant buildings) and technology (e.g. forecasting services), the cumulative impacts of natural hazards persist in detrimentally affecting the lives $(50,000$ people still die on average annually) and livelihoods of millions of people every year (Ritchie and Roser 2018). In this context, extreme value analysis provides a powerful statistical framework to analyse, understand and predict natural hazard events (Coles 2001).

The biennial Advances in Extreme Value Analysis and Application to Natural Hazards (EVAN) international conference series aims to: (1) bring together and promote interchange between the diverse community of research scientists, students, practitioners and stakeholders concerned with the complex and inter-disciplinary topic of natural hazard events; (2) encourage the transfer of state-of-the-art and best practice extreme value approaches and tools used by people working in various disciplines; and (3) promote an integrated approach to consider multi-hazard interactions and compounding effects (Zscheischler et al. 2018). The topics covered at the EVAN conferences include: description of probabilistic models that are useful in extreme value problems and applications, non-stationary extreme value analyses, multivariate extreme value statistics, spatial/regional analysis of extreme values, extreme value analysis from a climate perspective, uncertainties in extreme value analyses, risk analysis and adaptation, and resilience and sustainability, across a wide range of geophysical variables (i.e. temperature, rainfall, flows, sea level, winds, surface ocean waves, snow) and natural hazards (i.e. floods, windstorms, wave storms, heat waves, droughts, earthquakes, landslides). The 15 papers in this special issue derive from talks given at the 3rd EVAN conference that took place in Southampton, UK, from 12 to 14 September 2017.

The first two contributions to this special issue deal with the challenge of defining extreme events. Mazas (2019) presents an 'event approach' that provides a comprehensive

Ivan D. Haigh

I.D.Haigh@soton.ac.uk

1 School of Ocean and Earth Sciences, National Oceanography Centre, University of Southampton, European Way, Southampton SO14 3ZH, UK

2 Department of Civil, Environmental, and Construction Engineering, National Center for Integrated Coastal Research, University of Central Florida, 12800 Pegasus Drive, Suite 211, Orlando,

FL 32816-2450, USA 
framework for univariate and multivariate analyses for assessing extremes in different fields of environmental studies. The formal framework is based on the intimate link between sampling, event and the definition adopted for the return period, probability of exceedance or probability of occurrence. Although meteo-oceanographic variables were used to develop, test and apply this framework, Mazas (2019) argues that its relevance is independent of the nature of the natural phenomena that are considered and could be applied to other environmental variables, and beyond (e.g. in finances). Guanche García et al. $(2018 \mathrm{a}, \mathrm{b})$ propose a novel methodology to detect abnormal events within multivariate environmental data. They consider five biosphere variables from a preliminary version of the Earth System Data Cube, namely: Gross Primary Productivity, Latent Energy, Net Ecosystem Exchange, Sensible Heat and Terrestrial Ecosystem Respiration. Their results show that their new method is able to detect historic events and also provides a useful tool to define sensitive regions.

The instrumental records, to which extreme value analysis methods are applied, often cover only short time periods (several decades). Therefore, using short datasets for estimating high return periods (e.g. 1000-year return level) is challenging. The next two contributions deal with using historical information (over several centuries) to extend natural disaster catalogues and improve the estimation of higher return period values. Giloy et al. (2018) describe a historic database of storm and storm surges that occurred in Dunkirk, northern France. This database contains 73 events for the period from 1507 to 2000. Within the database, seven events that occurred between 1778 and 1846 were analysed in detail and skew surge values were estimated. The strategy used by the authors to quantify historic levels and estimate skew surge levels relies on the descriptive data available and puts it into historical and geographical context using auxiliary sources such as historic maps, engineer's reports or sketches of quays or dikes. Hamdi et al. (2018) develop a new approach that incorporates both regional and historical records around the coast of France and southern UK, to estimate extreme storm surges at La Rochelle, France, a site with a short sea-level data record. By applying a regional frequency model, using historical storm surges, they find that the 100-year return level at this site is $30 \mathrm{~cm}$ higher than when estimated using classical extreme value approaches.

The next six contributions deal with flooding. Using an integrated 1D-2D hydrodynamic model, Pasquier et al. (2018) assess the sensitivity of flooding on The Broads, on the eastern coast of the UK, to combined fluvial, tidal and coastal sources. They found that while flooding was primarily driven by increased mean sea levels, combined events (e.g. compound events) exacerbated the flooded area by $5-40 \%$ and average depth by 10-32\%. Bacopoulos (2018) assesses the extreme water levels that were induced by Hurricane Irma in 2017, around the coastline of Florida, USA. His paper shows how the peninsular shape of Florida creates a geographical setting where simultaneous extreme low and high waters can occur. Hurricane Irma's storm tide was extreme in varied ways, with a record-breaking low water of $-2.34 \mathrm{~m}$ (relative to mean sea level) and estimated return period of 283 years on the gulf coast and high water of $1.81 \mathrm{~m}$ (relative to mean sea level) and estimated return period of 110 years on the east coast (Mayport). Pham et al. (2019) use tide gauge records to characterize the spatial and temporal variations of extreme sea level around the low-lying and densely populated South China Sea coastline, by applying a dynamic linear model for the generalized extreme value distribution. Their study provides new insight into the dynamic relationships between extreme sea level, mean sea level and the tidal cycle in the South China Sea, which contributes to preparing for coastal risks at multi-decadal timescales. Using present (1980-2016) and near-future (2021-2024) storm surge modelling results for the northeast Atlantic, 
Fortunato et al. (2018) assess the evolution of extreme storm surges and sea levels along the Atlantic Iberian coast. Their results highlight that the impact of the increase in storminess on the extreme sea levels and coastal flooding will be modest, and the growth in extreme sea levels will be dominated by mean sea-level rise. Hounkpè et al. (2019) examine how changes in land use/land cover influence flood frequency and magnitude, using the Zou Catchment in the Benin Republic as a case study. Their study is among the first to establish a strong statistical relation between flood severity/frequency and agricultural land expansion and natural vegetation reduction. Galiatsatou et al. (2019) investigate the changes in the joint probabilities of extreme marine variables with time at selected sites in the Aegean Sea. They do this in order to assess design water levels at the shoreline under the effect of a possible realization of climate change.

The next contribution, by Beirlant et al. (2018), deals with estimating the maximum possible earthquake magnitude using extreme value methodology. They investigate the performance of nine different estimators of the endpoint of the extreme value distribution and applied it to the estimation of the maximum possible seismic event magnitude generated by gas production in the Groningen gas field in the Netherlands. Their analysis includes a comparison of extreme value theory-based estimators, non-parametric estimators and a parametric estimator.

The final four contributions deal with extreme temperatures and rainfall. Parey et al. (2018) describe a new approach for the estimation of hot temperature return levels in the future taking climate change into account. Their approach allows the estimation of return levels from the standardized values, using the entire length of the available observation periods, because it is not necessary anymore to restrict the period in order to be able to neglect the trend in a first approximation. This has the advantage of making the estimates of extreme value distribution parameters more robust. Gabda et al. (2018) describe a strategy for improving the inference for statistical models for the distribution of annual maxima observed temperature data, with a particular focus on past and future trend estimation. Their approach takes advantage of the additional information from climatological model data with a longer time period to address stochastic uncertainty together with an ensemble of climate model runs to quantify physical modelling uncertainty. Using records from 52 meteorological stations in Jiangsu Province, southeast China, Huang et al. (2018) assess the space and time changes of characteristics in rainfall erosivity in the region. Their results showed that Jiangsu Province could be divided into three major sub-regions (northern, central and southern areas) with different temporal variations in annual rainfall erosivity. Thasneem et al. (2019) analyse the variation of extreme precipitation in the Chaliyar river basin, in Indian. They calculate and compare return periods of precipitation for three future time periods (2010-2039, 2040-2069 and 2070-2099) estimated from the ensemble averaged projections of five global climate model-regional climates.

Overall, these excellent papers illustrate the multi-disciplinary nature of extreme value analysis research in the context of natural hazards. Collectively, the articles in this special issue represent an interesting range of perspectives and original studies that contribute to understanding and advancing the application of extreme value analysis to natural hazards, across a wide range of time and space scales. Enjoy reading them.

Acknowledgements We would like to thank Editors-in-Chief of Natural Hazards: T.S. Murty, V. Schenk and F. Franco, P. van Steenbergen and R. Murali for all their help, as well as the journal's publisher Springer Nature for their support. We also would also like to thank all the reviewers who donated their valuable time to provide useful comments to help the authors further improve the contents of their papers. 


\section{References}

Bacopoulos P (2018) Extreme low and high waters due to a large and powerful tropical cyclone: Hurricane Irma (2017). Nat Hazards. https://doi.org/10.1007/s11069-018-3327-7

Beirlant J, Kijko A, Reynkens T et al (2018) Estimating the maximum possible earthquake magnitude using extreme value methodology: the Groningen case. Nat Hazards. https://doi.org/10.1007/s1106 9-017-3162-2

Coles S (2001) An introduction to statistical modeling of extreme values. Springer Series in Statistics

Fortunato AB, Meredith EP, Rodrigues M et al (2018) Near-future changes in storm surges along the Atlantic Iberian coast. Nat Hazards. https://doi.org/10.1007/s11069-018-3375-Z

Gabda D, Tawn J, Brown S (2018) A step towards efficient inference for trends in UK extreme temperatures through distributional linkage between observations and climate model data. Nat Hazards. https://doi. org/10.1007/s11069-018-3504-8

Galiatsatou P, Makris C, Prinos P, Koddinos D (2019) Nonstationary joint probability analysis of extreme marine variables to assess design water levels at the shoreline in a changing climate. Nat Hazards. https ://doi.org/10.1007/s11069-019-03645-w

Giloy N, Hamdi Y, Bardet L et al (2018) Quantifying historic skew surges: an example for the Dunkirk Area France. Nat Hazards. https://doi.org/10.1007/s11069-018-3527-1

Guanche García Y, Shadaydeh M, Mahecha M et al (2018a) Extreme anomaly event detection in biosphere using linear regression and a spatiotemporal MRF model. Nat Hazards. https://doi.org/10.1007/s1106 9-018-3415-8

Guanche García Y, Shadaydeh M, Mahecha M et al (2018b) regression and a spatiotemporal MRF model. Nat Hazards. https://doi.org/10.1007/s11069-018-3415-8

Hamdi Y, Duluc CM, Bardet L et al (2018) Development of a target-site-based regional frequency model using historical information. Nat Hazards. https://doi.org/10.1007/s11069-018-3237-8

Hounkpè J, Diekkrüger B, Afouda AA et al (2019) Land use change increases flood hazard: a multi-modelling approach to assess change in flood characteristics driven by socio-economic land use change scenarios. Nat Hazards. https://doi.org/10.1007/s11069-018-3557-8

Huang J, Zhang F, Hu Z et al (2018) Climatology of rainfall erosivity during 1961-2012 in Jiangsu Province, southeast China. Nat Hazards. https://doi.org/10.1007/s11069-018-3391-z

Löw P (2018) Hurricanes cause record losses in 2017-The year in figures http://bit.do/eK63r. Accessed 15 May 2019

Mazas F (2019) Extreme events: a framework for assessing natural hazard. Nat Hazards. https://doi. org/10.1007/s11069-019-03581-9

Parey S, Hoang TTH, Dacunha-Castelle D (2018) Future high-temperature extremes and stationarity. Nat Hazards. https://doi.org/10.1007/s11069-018-3499-1

Pasquier U, He Y, Hooton S et al (2018) An integrated 1D-2D hydraulic modelling approach to assess the sensitivity of a coastal region to compound flooding hazard under climate change. Nat Hazards. https:// doi.org/10.1007/s11069-018-3462-1

Pham DT, Switzer AD, Huerta G et al (2019) Spatiotemporal variations of extreme sea levels around the South China Sea: assessing the influence of tropical cyclones, monsoons and major climate modes. Nat Hazards. https://doi.org/10.1007/s11069-019-03596-2

Ritchie H, Roser M (2018) Natural disasters https://bit.ly/2NLvvvf. Accessed 15 May 2019

Thasneem AS, Chthra NR, Thampi SG (2019) Analysis of extreme precipitation and its variability under climate change in a river basin. Nat Hazards. https://doi.org/10.1007/s11069-019-03664-7

Zscheischler J et al (2018) Future climate risk from compound events. Nat Clim Chang 8:469-477. https:// doi.org/10.1038/s41558-018-0156-3

Publisher's Note Springer Nature remains neutral with regard to jurisdictional claims in published maps and institutional affiliations. 